\title{
Prevalence of ADRs and Associated Factors of Antiretroviral Treatment on HIV Positive Adults at Jush
}

\author{
Ramanjireddy Tatiparthi*, Yitagesu Mamo \\ Department of Pharmacy, College of public health and medical sciences, Jimma University, Jimma, southwest, Ethiopia.
}

\begin{abstract}
A cross sectional study is designed to assess the prevalence of adverse drug reactions and its associated factors on who are already under Highly Active Antiretroviral Therapy. Considerable progress has been made to access the therapy since the decades, even though; currently five million people do not have an access to HIV therapy, it just represents $35 \%$ only. The objective of present research is to assess the prevalence of ADRs and its associated factors on HAART at Jimma University Specialized Hospital. The data was pooled by reviewing the previous clinical records of HIV positive adults, who admitted from January 2010 to December 2013. The total sample size is found to be 233 . The results showed from the total of 233 patients, $70.8 \%$ were developed ADRs and the most of them are nausea, vomiting and diarrhea at $18.9 \%, 15 \%$ and $7.7 \%$ respectively, and the least one is hepatotoxicity at $0.43 \%$ only. The prevalence of ADRs of HAART was high at JUSH. Low CD 4 cell count was identified at initial stages and concomitant use of cotrimoxazole with ARVs is the major risk factor for ADRs. Thus, health care providers working in the JUSH ART clinic need to monitor the $\mathrm{CD}_{4}$ count of patients, particularly those treated with combination of antibiotics and ARVs.
\end{abstract}

Key words: Adverse drug reactions, associated factors, nausea, vomiting, HAART, $\mathrm{CD}_{4}$ count, JUSH.

\section{INTRODUCTION}

Antiretroviral medicines are medications for the treatment of infection by retroviruses, primarily HIV. When several such medicines, typically three or four, are taken in combination, the approach is known as Highly Active Antiretroviral Therapy (HAART). Considerable progress has been made in providing global access to Antiretroviral Therapy (ART), with five million people currently on antiretroviral medicines around the world. This is a major public health achievement, however, still represents only $35 \%$ of the people who need HIV therapy now. ${ }^{1}$

In general, the use of HAART has had an important impact on the course and treatment of the disease and disease-related morbidity of HIV-infected patients, increas- ing their life span and quality of life. ${ }^{2}$ However, it has been reported that these advantages have been accompanied by a marked increase in the number of adverse drug reactions (ADRs), including minor and serious cutaneous ADRs. ${ }^{3}$

The present trepidation of the WHO is, the people are living outside of antiviral treatment (ART) in low and middle income countries. ${ }^{4}$ In 2001, United Nations General Assembly unanimously legitimates the Declaration of Commitment on HIV/AIDS and further, in 2003, WHO launched the "3 by 5 " initiative program to fight against AIDS, Tuberculosis and Malaria.

Between 2001 and 2005, antiretroviral therapy is amplified more than fivefold from 240,000 to 1.3 million. ${ }^{5}$ As of June 2005, 21
DOI: 10.5530/ijopp.7.4.3

Address for correspondence: Dr. Ramanjireddy Tatiparthi,

Associate professor, Department of Pharmacy, Jimma University, PO378, Jimma, Ethiopia. Phoneno:+251-931977170 ramanjireddy.brahmareddy@ ju.edu.et

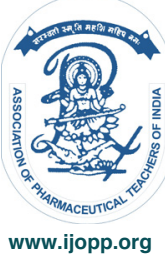


countries were provided the antiretroviral treatment to at least $50 \%$ of patients. The WHO estimated that by the end of 2005, out of 6.5 million people, only 1.3 million were received it. ${ }^{6,7}$

Antiretroviral therapy more than doubled in sub-Saharan Africa in 2005, with one in six received the treatment, with a coverage level of $50 \%$ or more have been achieved in some countries such as Botswana and Uganda, while in others levels remained at less than $10 \%$. As at the same time, 250,000 to 350,000 deaths were averted even in the areas are in the treatment access.

By March of 2005, Global Fund funded free ART service has been started at least at one site in all regions. Currently, 132 sites are providing ART services. ${ }^{8} \mathrm{Up}$ to August 8, 2006, a total of 73,540 people living with HIV/AIDS were enrolled for HIV/care out of which 45,595 had been started on ART. Currently 35,460 are on ART. Some 10,135 (22.2\%) constitute lost to follow up, died, and stopped treatment due to treatment failure or other problems.

In Ethiopia, 1.32 Million people have been infected with HIV/AIDS in 2005 and 134,450 have died of AIDS including 20,929 children. Currently, some 277,757PLWHA including 213,306 adults are in need of ART. In January 2005, the Ethiopian government launched a program on "Accelerating Access to HIV/ AIDS Treatment" to providing the universal access to ART by the year 2008. The program enrolled 100,000 patients by the end of 2006 and a total of 132 facilities were started across the country. The $22.2 \%$ of the patients missed follow up the treatment due to failure or other problems. ${ }^{9}$

In 2009, WHO estimated 33.4 million people are suffering with HIV/AIDS, there were 2.7 million new HIV infections per year and 2.0 million annual deaths occurring due to AIDS. ${ }^{10}$ According to UNAIDS reports in 2010, the Sub-Saharan Africa region is more seriousness exaggerated by the HIV, more than $67 \%$ of the people infected with HIV and $72 \%$ of patients have died in 2008 due to AIDS. ${ }^{11}$

The success of the anti-retroviral treatment is highly dependent on motivation of HIV positive individuals to adhere to complex ARV regimens. ${ }^{12}$ Unfortunately, up to $25 \%$ of patients discontinue their initial HAART regimen because of toxic effects, noncompliance or treatment failure within the first 8 months of therapy. ${ }^{13}$ The occurrence of side effects can vary dramatically among different people. ${ }^{14}$ Continuous evaluation will be the benefit of ART help to achieve the ultimate goal of making safer and more effective treatment to the patients ${ }^{15,16}$ by constituting the ADRs monitoring centers, responsible for collecting, compiling and analyzing any ADRs information reported by health profession- als. Based on this information, risk-benefit evaluations are made and safety measures are taken.

In Ethiopia, there has been an ADR Monitoring Division organized at the Drug Administration and Control Authority (DACA) since 2003. The Division has so far received 110 ADR reports out of which, 60 were ADRs on Anti-Retroviral Drugs. ${ }^{17}$

Therefore, the aim of this study was to gain knowledge on the profile of ADR associated with ARV drugs, the burden of adverse drug reactions of ART in our setup and factors associated with it, with the ultimate goal of improving the tolerability and effectiveness of HIV treatment.

\section{Statement of the problem}

Different types of antiretroviral adverse drug reactions occur commonly among patients. Some of ADRs occur early in the course of the therapy, others at the end of treatment. These ADRs vary in their severity; a common cause is poor adherence. Short-term threats are probable to the successful maintenance of HAART. For the last five years of ARV treatment, some of ADRs are observed in the course of therapy. The present study targets the adult patients having HIV/AIDS who already started HAART therapy at JUSH.

\section{Significance of the study}

Once antiretroviral therapy is initiated, patients generally remain on medications indefinitely. A switch in the antiretroviral (ARV) regimen is often necessary because of both acute and chronic toxicities, concomitant clinical conditions and virological failures need to switch other medications. ${ }^{18}$ This study conducted to assess the fundamental causes for switching the treatment. It is also provides a valuable assistance to the concerned organizations, especially for the health facilities in handling the causes for switching. Moreover, this research is to create a baseline for study of causes.

More than 95\% treatment adherence levels are required to maintain virologic suppression in people on a combination of ARV drugs, but most studies showed only $40 \%$ to $60 \%$ of adherence. The most common reasons for non-adherence are complexity of medication regimens, the difficulty of integrating treatment schedules into their daily activities, side effects, uncertainties about HIV disclosure, and poor memory in medication. Higher percentage of patients in Africa, are falling into the category of poor adherers. ${ }^{19}$ The recent findings from African countries showed that patients in Africa are also able to achieve wonderful adherence. ${ }^{20-22}$

In an assessment of adherence among the patients at the national defense force hospitals, the average adherence rate to antiretroviral medication was found to be 
$82.8 \%{ }^{23}$ In another similar study, $81.2 \%$ of patients were $>95 \%$ adherent by self-report in the week before the assessment and $78.9 \%$ claimed never to have missed a single dose over the past week. ${ }^{24}$ The highest rate of adverse reaction $(16.8 \%)$ was also found in the nonadherent patients than in the adherent patients $5.8 \%$.

\section{ADR and Magnitude of ADRs of ARV drugs}

USFDA defined serious adverse event as one when the patient outcome has one of the following events: death, life-threatening, hospitalization, resulted in switching/ discontinued and disability (i.e., significant impairment, damage or disruption) in the patient's body function/ structure. ${ }^{25}$ ADRs may occur following a single dose or prolonged administration of medicine or result from the combination of two or more medicines.

HIV-infected patients at the beginning of the antiretroviral treatment can frequently show a wide variety of adverse drug effects such as rashes, hyper pigmentation, hair loss, hypersensitivity reactions, injection site reaction, urticarial reaction, erythema multiform, toxic epidermal necrolysis (TEN) or Stevens-Johnson syndrome (SJS). ${ }^{26}$ Further, it has been reported that up to $80 \%$ of HIV-infected patients experience ADRs at some point during their therapy, presumably as a result of immune dysregulation, altered medicine metabolism and/or polypharmacy. ${ }^{27}$ However, HIV-infected patients are more prone to developing cutaneous reactions than the non-infected population. ${ }^{28}$ It has been reported that the severity of cutaneous adverse reactions varies greatly, and some may be difficult to manage. Cutaneous adverse drug reactions have been reported with all antiretroviral medications. So far, clinical trials have not given conclusive safety results. It is critical to be very cautious when including these agents into HIV treatment regimens.

Most of the ADRs are relatively mild can be disappear, if the drug is stopped, or some gradually subside as the body adjusts to the drug. Other side some of ADRs are lasting longer. In every 3-7\% of hospital admissions, at least one ADR estimated in the United States. ${ }^{29}$

The safety profile of ARV drugs and magnitude of ADRs among patients on ART in Ethiopia is virtually unknown. None the less, patients on HAART suffer from ADRs. Several factors such as the sex of the patient, clinical condition, drug classes or agent used, pre- existing illness like liver dysfunction, are known to be associated with the occurrence, type and severity of ADRs among patients taking ART. ${ }^{30}$

The use of HAART has had an important impact on the course and treatment of the disease and diseaserelated morbidity of HIV-infected patients, increasing their life span and quality of life. However, it has been reported that these advantages have been accompanied by a marked increase in the number of adverse drug reactions (ADRs), including minor and serious adverse drug reactions. ${ }^{31}$

Thus, it is expected that these and other several unknown factors could also affect the prevalence of ADRs among patients taking ART in our setup. Therefore, this study tried to assess the prevalence of ADRs and identify factors associated with patients taking ARV drugs at JUSH.

\section{MATERIAL AND METHODS}

\section{Study design}

This study is conducted in the period of January 2014 to Feb 2014 at JUSH; it is $350 \mathrm{~km}$ away from Add is Ababa to the south west of Ethiopia. It was an institution based cross sectional study by reviewing clinical records of HIV positive adult patients on HAART from January 2010 to December 2013. Data abstract form was used to collect information on adult demographics, WHO clinical stage, $\mathrm{CD}_{4}$ count, initiation and change of regimen, and duration of therapy.

\section{Sampling size and study variables}

The total of 2525 adult HIV positive patients registered from January 2010 to December 2013 for HAART treatment in ARV clinic at JUSH. From 2525 patients, 233 were selected for the study based on inclusion criteria, which aged greater than or equal to 15 years on HAART and those who are greater than or equal to 6 months in duration of therapy. Any patient with identified with unintended overdose, missing clinical record, incomplete data were excluded from the study. The sample size for the study was determined based on patients taking ART develop ADRs from research done in Ambo zonal hospital. ${ }^{32}$ Taking critical value at $95 \%$ confidence level, degree of precision 0.05 , missing or incomplete record by adding $10 \%$ of the contingency ( 21 patients) minimum actual sample size is 233 . Every 10th patient's clinical record is included in the sample. Those patient's clinical records which did not fulfill the inclusion criteria or missing were substituted with the next patient on the list. The Independent variables are socio-demographic characteristics, Clinical stage at the beginning of treatment, type of regimen, and usage of concomitant regimens. The dependent variables are typed and frequency of ADRs.

\section{Data collection}

The data were analyzed by entering into SPSS version 16.0. Descriptive statistics were generated to meet the objective of the study. The estimated prevalence of ADRs was presented as in the form of tables, charts 
and graphs. The quality of the study is maintained by the proper training to the data collectors on patient information sheets and clinical records. Supervision has made by the principal investigator to check up by accurate filling of data abstract forms. A pilot study also conducted to maintain the quality of the information. Before the data abstraction, the study is ethically approved by the JUSH in writing consent. The total information was kept confidential.

\section{RESULTS}

\section{Socio demographic characteristics}

From a total of 233 HIV positive adult patients on HAART treatment, 141 (60.5) were females, 211 $(90.6 \%)$ aged between 15-49 years and $22(9.4 \%)$ aged greater than 50 years. of 233 patients $117(50.2 \%)$ have a BMI in the range of $17-24$ and $55(23.6 \%)$ have more than 24, out of 233 patients $114(48.9 \%)$ have primary or secondary education, $75(32.2 \%)$ patients were illiterates and $44(18.9 \%)$ was above grade 12 th. $139(59.66 \%)$ were married and $9(3.7 \%)$ were divorced. Out of 233 patients $136(58.4 \%)$ living in urban areas and 97 (41.6\%) were in rural. the socio demographic characteristics of HIV positive adult patients can see in Table 1.

\section{Clinical stage, $\mathrm{CD}_{4}, \mathrm{BMI}$ at the beginning of ARV treatment}

Out of 233 patients, most of the patients, $126(54.1 \%)$ were at WHO clinical stage III and $66(28.3 \%)$ were

\begin{tabular}{lcc}
$\begin{array}{l}\text { Table 1: Socio-demographic characteristics of the } \\
\text { patients on HAART }\end{array}$ & $\begin{array}{c}\text { Frequency } \\
\text { Demographic characteristics }\end{array}$ \\
\begin{tabular}{lcc}
\multicolumn{2}{c}{ Variables } & Categories
\end{tabular} \\
$\begin{array}{l}\text { Age of the patient } \\
\text { in years }\end{array}$ & $15-49$ & $219(94.0)$ \\
Sex of the patient & or $=50$ & $14(6)$ \\
& Male & $92(39.5)$ \\
Initial BMI of the & Female & $141(60.5)$ \\
patient & $<17$ & $61(26.2)$ \\
& $17-24$ & $117(50.2)$ \\
Marital status of & $>24$ & $55(23.6)$ \\
the patient & Single & $71(30.9)$ \\
& Married & $139(59.66)$ \\
& Divorced & $9(3.86)$ \\
Educational & Widowed & $13(5.58)$ \\
status & No formal education & $75(32.2)$ \\
& Primary & $82(35.2)$ \\
Residence of the & Secondary & $32(13.7)$ \\
patient & Tertiary & $44(18.9)$ \\
\hline & rural & $97(41.6)$ \\
& urban & $136(58.4)$ \\
\hline
\end{tabular}

Table 2: Clinical stage of patients at the beginning of ARV

\begin{tabular}{lcc}
\hline \multicolumn{2}{c}{ Clinical stage } & Frequency (\%) \\
\hline \multirow{3}{*}{$\begin{array}{l}\text { WHO clinical } \\
\text { stage }\end{array}$} & Stage I & $22(9.4)$ \\
& Stage II & $66(28.3)$ \\
& Stage III & $126(54.1)$ \\
& Stage IV & $19(8.2)$ \\
Functional state & Work & $87(37.3)$ \\
& Ambulatory & $132(56.7)$ \\
& Bed ridden & $14(6.0)$ \\
CD ${ }_{4}$ count & $<\mathbf{2 0 0}$ & $59(25.3)$ \\
& $\mathbf{2 0 0 - 4 0 0}$ & $136(58.4)$ \\
& $>\mathbf{4 0 0}$ & $38(16.3)$ \\
BMI $^{*}$ & $<\mathbf{1 7}$ & $61(26.18)$ \\
& $\mathbf{1 7 - 2 4}$ & $118(50.64)$ \\
\hline
\end{tabular}

at stage II. Among 233 patients, 136 (58.4\%) had $\mathrm{CD}_{4}$ count of $200-400$ cells $/ \mathrm{mm}^{3}$ and $59(25.3 \%)$ patients had more than 200 cells $/ \mathrm{mm}^{3}$ at the initiation of HAART. From a total of 233 patients, 132 (56.6\%) were ambulatory and the $14(6 \%)$ were bed ridden in condition, depicted in the Table 2.

From a total of 233 patients, 118 (50.6\%) of the patients had BMI of between or equal to 17 and 24, $61(26.2 \%)$ patients had BMI below 17 and the rest 54 (23.2\%) patients had BMI above 24 showed Table 2.

From a total of 233 patients $131(56.2 \%)$ patients started with TDF/3TC/EFV, 63 (27\%) with ZDV/3TC/NVP and $17(7.3 \%)$ with TDF/3TC/EF. D4T/3TC/EFV was the list prescribed regimen, 5 (2.1\%) showed in Figure 1.

\section{ADRs and associated factors}

Most patient with $\mathrm{CD}_{4}<200$ cells $/ \mathrm{mm}^{3}$ developed ADR (86.4\%), followed with $\mathrm{CD}_{4}$ 200-400 cells $/ \mathrm{mm}^{3}$ $(68.4 \%)$ and $\mathrm{CD}>400$ cells $/ \mathrm{mm}^{3}(64.7 \%)$ patients. (With a p value $=0.009)$. Among the patients that developed ADRs, 161 (69.09\%) patients were on cotrimoxazole prophylaxis shown in Table 3.

Among 165 patients that developed adverse drug reactions, (41.6\%) developed GI tract ADR followed by CNS ADR (insomnia and night mare), $(12 \%)$ and anemia (4.3\%). ZDV/3TC/EFV and TDF/3TC/EFV were the main regimen caused gastro intestinal $\mathrm{ADR}(60 \%)$ and $(48 \%)$ of the regimen respectively. TDF/3TC/EFV and ZDV/3TC/EFV was mainly caused CNS adverse drug reaction $(20.7 \%)$ and $(10 \%)$ of the regimen respectively, can be seen in Table 4. The duration of the patients to develop ADRs has been identified and graphed in Figure 2. 


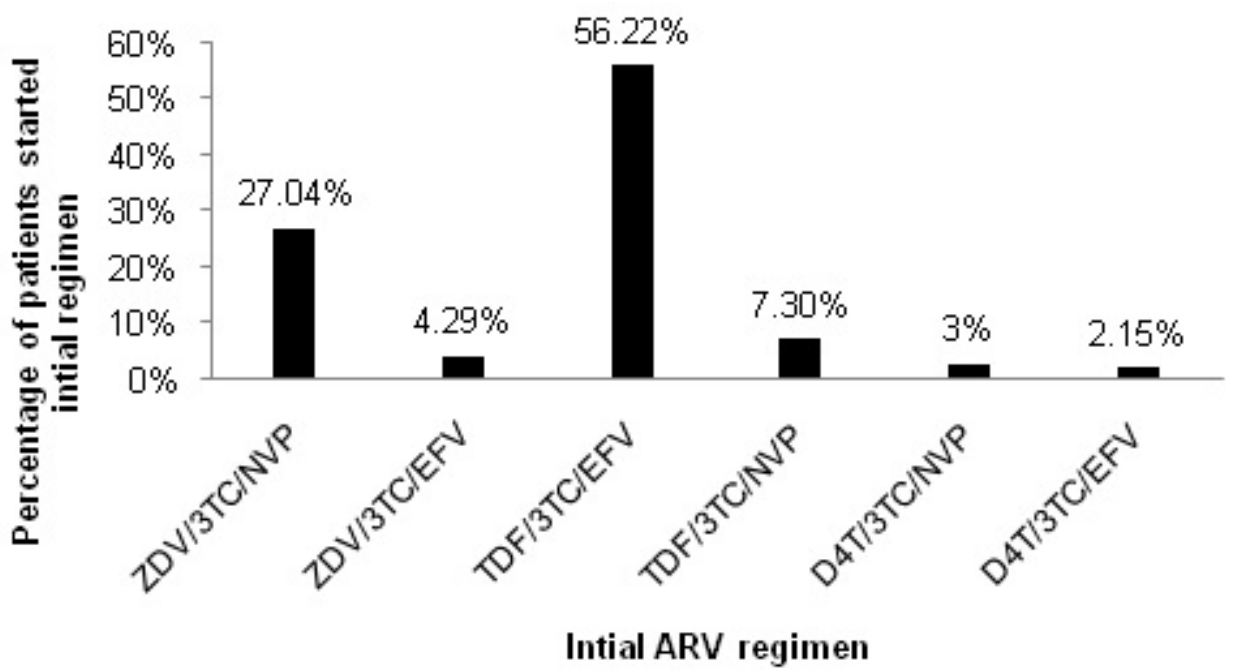

Figure 1: ARV regimen the patient has taken at initiation of treatment

\begin{tabular}{l} 
Table 3: Adverse drug reactions and $\mathbf{C D}_{\mathbf{4}}$ count of the patient \\
\cline { 2 - 5 } \\
\cline { 2 - 5 }
\end{tabular}

\section{Table 4: ARD regimen and prevalence of ADR developed at JUSH}

\begin{tabular}{|c|c|c|c|c|c|c|c|}
\hline \multirow[b]{2}{*}{ ADRs } & \multicolumn{6}{|c|}{ INITIAL ARV } & \multirow[b]{2}{*}{ Total } \\
\hline & ZDV/3TC/NVP & ZDV/3TC/EFV & TDF/3TC/EFV & TDF/3TC/NVP & D4T/3TC/NVP & $\begin{array}{c}\text { D4T/3TC/ } \\
\text { EFV }\end{array}$ & \\
\hline $\begin{array}{l}\text { Peripheral } \\
\text { neuropathy }\end{array}$ & $4.8 \%$ & - & - & - & - & $60.0 \%$ & $2.6 \%$ \\
\hline Hepatotoxicity & $1.6 \%$ & - & - & - & - & & $0.4 \%$ \\
\hline $\begin{array}{l}\text { Lipid } \\
\text { dystrophy }\end{array}$ & - & - & - & - & $14.3 \%$ & $20.0 \%$ & $0.9 \%$ \\
\hline Diarrhea & $9.5 \%$ & $20.0 \%$ & $5.3 \%$ & $11.8 \%$ & $14.3 \%$ & - & $7.7 \%$ \\
\hline Nightmare & - & & $11.5 \%$ & - & - & - & $6.4 \%$ \\
\hline Nausea & $15.9 \%$ & $30.0 \%$ & $22.1 \%$ & $11.8 \%$ & - & - & $18.9 \%$ \\
\hline Vomiting & $7.9 \%$ & $10.0 \%$ & $20.6 \%$ & $11.8 \%$ & - & - & $15.0 \%$ \\
\hline Headache & - & - & $5.3 \%$ & $17.6 \%$ & - & - & $4.3 \%$ \\
\hline Fatigue & $1.6 \%$ & - & $0.8 \%$ & - & $14.3 \%$ & - & $1.3 \%$ \\
\hline Skin rash & $4.8 \%$ & - & $3.8 \%$ & - & - & - & $3.4 \%$ \\
\hline Insomnia & - & $10.0 \%$ & $9.2 \%$ & - & - & - & $5.6 \%$ \\
\hline Anemia & $7.9 \%$ & $10.0 \%$ & $3.1 \%$ & - & - & - & $4.3 \%$ \\
\hline Total & $54.0 \%$ & $80.0 \%$ & $81.7 \%$ & $52.9 \%$ & $42.9 \%$ & $80.0 \%$ & $70.8 \%$ \\
\hline
\end{tabular}




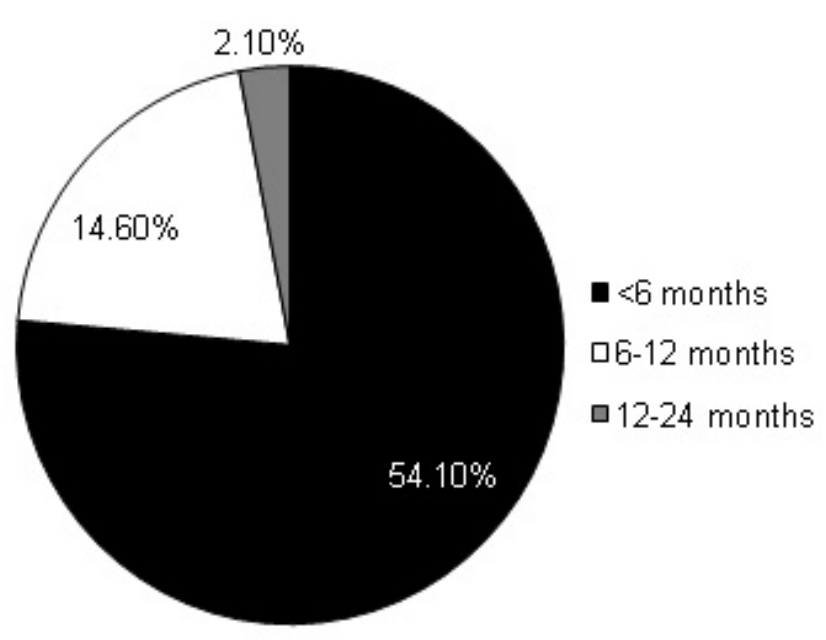

Figure 2: Duration patient on ARV regimen before developed ADRs

\section{DISCUSSION}

The use of HAART has had an important impact on the course and treatment of the disease and diseaserelated morbidity of HIV-infected patients, increasing their life span and quality of life. However, it has been reported that these advantages have been accompanied with marked increase in the number of ADRs, including minor and serious ADRs.

This study showed the prevalence ADRs and its factors related in ART clinic at JUSH. The overall prevalence of ADRs in this study was $70.8 \%$. In line of specific prevalence's observed high to low, for TDF/3TC/EFV (81.7\%), ZDV/3TC/EFV (80\%), and D4T/3TC/NVP $(80 \%)$, these results are not comparable with a study conducted at Nekemte hospital in Ethiopia33 is 46.5\% were due to $\mathrm{D} 4 \mathrm{~T} / 3 \mathrm{TC} / \mathrm{NVP}$, and the remaining $29.8 \%$, $12.8 \%, 5.3 \%, 3.5 \%, 1.8 \%$, and $0.9 \%$ were $\mathrm{D} 4 \mathrm{~T} / 3 \mathrm{TC} /$ EFV, AZT/3TC/EFV, TDF/3TC/EFV, AZT/3TC/ NVP, TDF/3TC/NVP and AZT/3TC/LPV respectively.

D4T containing regimens accounted peripheral neuropathy and lipid dystrophy are $60 \%$ and $20 \%$ respectively, while 3TC containing regimens accounted for diarrhea and ZDV containing regimens accounted for hepatotoxicity observed.

This prevalence was very high compared to $(26.75 \%)$ reported in India ${ }^{34}$ and $6.7 \%$ in U.S.A at $95 \%$ CI. ${ }^{35}$ This may because of exclusion of mild ADRs may be contributory to the low ADR in the study done in India, but lower when compare to study done in Ambo zonal hospital $^{36}$ is $81.5 \%$. There is another assessment of adherence to ARV therapy at the Ministry of National Defense Force hospitals showed that 54.0\% developed mild ADRs, ${ }^{37}$ it is also less than our study results.
Major of the ADRs, GI tract related accounted for $41.6 \%$ followed by CNS ADRs and anemia were $12 \%$ and $4.3 \%$ respectively, when compared to a study conducted in India, the most common ADRs were rash $(66 \%)$, hepatotoxicity $(27 \%)$ and anemia $(23 \%){ }^{38}$

In this study, majority of the patient in age group of 15-49 has been affected with more ADRs to ARV treatment. A study conducted in India showed age group $21-40$ years $(66.5 \%)$ has been more affected. ${ }^{39}$ This is because majority of the patients are in age between 15-49 years or reproductive age.

Most patients of that developed ADRs had $\mathrm{CD}_{4}<200$ cells $/ \mathrm{mm}^{3}$, when ARV was initially experienced more ADRs, when compared to patients with $\mathrm{CD}_{4}$ count $>200$ cells $/ \mathrm{mm}^{3}$ this is in line with the research done in India. ${ }^{39}$ Yet, most patients had $\mathrm{CD}_{4}$ between 200 and 400 cells $/ \mathrm{mm}^{3}$ in this study. This is in line with a research done in Ambo hospital. ${ }^{36} \mathrm{~A}$ significant association was observed between ADRs and ARV treatment regimen $(\mathrm{p}$ value $=0.00)$ and also between $\mathrm{CD}_{4}$ count and ADRs ( $\mathrm{p}$ value $=0.009$ ).

The prevalence of ADRs was high in females (43.6\%) as compared to male $(27.2 \%)$ patients. This was in line with a research done in Nigeria ${ }^{40}$ and Italy, ${ }^{41}$ (64\% vs 59) and $(67 \%$ vs. $61 \%)$ respectively. In another investigation found that women were at high risk of ADRs like neutropenia, hepatitis B and hepatitis C were significantly associated. ${ }^{42}$ The data Italian registry showed that the rates of side effects were higher among females $(67 \%$ vs. $61 \%)^{43}$

In this study TDF/3TC/EFV was the most common regimen that causes ADRs. In contrast to this finding, the research done in Nigeria has found ZDV/3TC/ NVP had high prevalence. This difference could be due to differences between prevalence of the drug prescribed, in this study the most prescribed drug was $\mathrm{TDF} / 3 \mathrm{TC} / \mathrm{EFV}(56.2 \%)$, but in research conducted in Nigeria it was ZDV/3TC/NVP(66.45\%).

Most of the patients on HAART treatment commonly suffer from ADRs. ${ }^{44,45}$ In our present research nausea and vomiting is the commonest ADRs, The toxicity rate at $80 \%$ while $\mathrm{D} 4 \mathrm{~T} / 3 \mathrm{TC} / \mathrm{EFV}$ is prescribed, this is greater than a study conducted in Ugand $a^{46}(50 \%)$, but it is in line with a study $79 \%$ in Kenya.

All antiretroviral drugs can have both short-term and long-term adverse events. The risk of specific side effects varies from drug to drug, from class to class, and from patient to patient. ${ }^{47} \mathrm{~A}$ review on HIV and drug allergy showed that drug-related rashes have been estimated to be 100 times more common in HIV-positive patients than in the general population, but in our research the rashes are only $3.4 \%$ 


\section{CONCLUSION AND RECOMMENDATION}

The prevalence of ADRs of ARV is high. Advanced stages of AIDS has highly related to the development of ADRs. Low $\mathrm{CD}_{4}$ cell count at treatment initiation is a risk factor for the occurrence of ADRs also, some of the recommendations has done following

- Health care providers working in the JUSH, ARV clinic, should monitor patients with laboratory findings for cause of ADRs, especially with concomitant medication

- Patients should be routinely request to check the $\mathrm{CD}_{4}$ count and renal function tests and glucose levels.

- As much as possible, clinicians should stick to the national guidelines to manage and follow up of patients, who receiving HAART.

- Patients should be educated on the possible ADRs of ARV drugs.

- Finally, further prospective study is recommended to overcome the limitations of retrospective cross sectional study and use of secondary data from clinical records with the existing clinical record keeping condition

\section{ACKNOWLEDGEMENT}

The authors thanks to Jimma University for sponsoring this study.

\section{REFERENCES}

1. Joint United Nations Programme on HIVIAIDS. AIDS scorecards: overview: UNAIDS report on the global AIDS epidemic 2010. UNAIDS; 2010.

2. Crum NF, Riffenburgh RH, Wegner S. Comparisons of causes of death and mortality rates among HIV-infected persons: analysis of the pre, early, and late HAART (highly active antiretroviral therapy) eras. J Acquir Immune Defic Syndr. 2006; 41(2): 194-200.

3. Calmy A. A new era of antiretroviral drug toxicity. Antivir Ther. 2009; 14(2): 16579.

4. Joint United Nations Programme on HIVIAIDS Staff, World Health Organization, and World Health Organization Staff. AIDS epidemic update, December 2006. World Health Organization; 2006.

5. Bartlett JA. Addressing the challenges of adherence. J Acquir Immune Defic Syndr. 2002; 29(1): S2-10.

6. Gilks CF, Crowley S, Ekpini R, Gove S, Perriens J, Souteyrand Y, et al . The WHO public-health approach to antiretroviral treatment against HIV in resource-limited settings. The Lancet 2006; 368(9534): 505-10.

7. Kloos, Helmut, Assefa Y, Adugna A, Mulatu MS, Mariam DH. Utilization of antiretroviral treatment in Ethiopia between February and December 2006: spatial, temporal, and demographic patterns. International Journal of health geo graphics. 2007; 6(1): 45.

8. Hladik W, Shabbir I, Jelaludin A, woldu A, Tsehaynesh M, Tadesse W. HIVIAIDS in Ethiopia: where is the epidemic heading? Sexually transmitted infections 2006; 82(S1): i32-5.

9. Holzemer WL, Corless IB, Nokes KM, Turner JG, Brown MA, Powell-Cope GM, et al. Predictors of self-reported adherence in persons living with HIV disease. AIDS Patient Care STDS 1999; 13(3): 185-97.
10. Un AIDs, W. H. O. AIDS epidemic update 2009. Geneva: Joint United Nations Programme on HIVIAIDS (UNAIDS) and World Health Organization WHO; 2009.

11. Joint United Nations Programme on HIVIAIDS. AIDS scorecards: overview: UNAIDS report on the global AIDS epidemic 2010. UNAIDS; 2010.

12. Ammassari A, Trotta MP, Murri R, Castelli F, Narciso P, Noto P, et.al. Correlates and predictors of adherence to HAART. JAIDS. 2002; 31(3): S123-7.

13. Montessori V, Press N, Harris M, Akagi L, Montaner SG. Adverse effects of antiretroviral therapy for HIV infection. CMAJ. 2004; 170(2): 229-38.

14. Liz Highleyman. Adverse Effects Associated with Antiretroviral Therapy. Bulletin for experimental AIDS treatment 2000; 356(9239): 1423-30.

15. Derseh, Alemayehu MD. Implementation of Anti-Retroviral Therapy (ART) pharmacy management information system in health facilities in Ethiopia. [Dissertation]. University of South Africa.; 2013.

16. Necho W, Worku A. Assessment of knowledge, attitude and practice of health professionals towards adverse drug reaction reporting and factors associated with reporting. J Pharmacov. 2014; 2: 135. doi:10.4172/2329-6887.1000135

17. Shankar PR, Subish P. Designing a spontaneous adverse drug reaction reporting form: an exercise for medical students. The International Journal of Risk and Safety in Medicine 2006; 18(2): 115-9.

18. Bristol, Nellie. New hopes for tackling HIVIAIDS in the USA. The Lancet 2008; 372(9653): 1869-70.

19. Warren S, Steve K, Tumani C. Antiretroviral therapy in Africa. BMJ. 2004; 328(7434): 280-2.

20. Orrell C, Bangsberg DR, Badri M, Wood R. Adherence is not a barrier to successful antiretroviral therapy in South Africa. AIDS. 2003; 17(9): 1369-75.

21. Byakika-Tusiime J, Oyugi JH, Tumwikirize WA. Ability to purchase and secure stable therapy are significant predictors of non adherence to antiretroviral therapy in Kampala, Uganda. 10th conference on Retroviruses and Opportunistic Infections. Boston, Massachusetts; 2003. February10-14.

22. Laurent C, Fatou N, Gueye NF. Long-term follow-up of a cohort of patients under HAART in Senegal. 10th conference on Retroviruses and Opportunistic Infections Boston, Massachusetts; 2003. February10-4.

23. Mengesha A. Assessment of adherence to antiretroviral therapy among 422 patients on ART at the ministry of national defense force hospitals [dissertation]. Ethiopia: Addis Ababa Univ; 2005. 18-22.

24. Tadios Y. Antiretroviral treatment adherence and its correlates among people living with HIVIAIDS on Highly Active Antiretroviral Therapy in Addis Ababa. Ethiopia: Addis Ababa Univ; 2005. 45-9.

25. Szarfman, Ana, Machado SG, O'Neill RT. Use of screening algorithms and computer systems to efficiently signal higher-than-expected combinations of drugs and events in the US FDA's spontaneous reports database. Drug Safety 2002; 25(6): 381-92.

26. Salazar AH, Rosales SPDL, Frausto SR, Criollo E, Dubon CA, Topete RO. Epidemiology of adverse cutaneous drug reactions. A prospective study in hospitalized patients. Arch Med Res. 2006; 37(7): 899-902.

27. González-Martín G, Yañez CG, González-Contreras L, Labarca J. Adverse drug reactions (ADRs) in patients with HIV infection. A prospective study. Int J Clin Pharmacol Ther. 1999; 37(1): 34-40.

28. Manzardo C, Zaccarelli M, Agüero F, Antinori A, Miró JM. Optimal timing and best antiretroviral regimen in treatment-naive HIV-infected individuals with advanced disease. J Acquir Immune Defic Syndr. 2007; 46(1): S9-18.

29. Bates, David W, Cullen DJ, Laird N, Petersen LA, Small SD, et al. Incidence of adverse drug events and potential adverse drug events: implications for prevention. JAMA. 1995: 274(1): 29-34.

30. Puro V, Cicalini S, Carli GD, Soldani F, Antunes F, Balslev U, et al. Post-exposure prophylaxis of HIV infection in healthcare workers: recommendations for the European setting. European Journal of epidemiology. 2004: 19(6): 577-84.

31. Calmy A, Hirschel B, Cooper DA, Carr A. A new era of antiretroviral drug toxicity. Antivir Ther. 2009; 14(2): 165-79.

32. Chelkeba L, Abdissa G. Assessment of ART adverse reactions and determinants at primary hospital in Ethiopia. Int J Basic Clin Pharmacol. 2013; 2(2): 208-15.

33. Hasen T. Acceptability of provider initiated HIV counseling and testing in pregnant mothers attending ANC at Nekemte town government health facilities. Sci Technol Arts Res J. 2012; 1(3): 24-30.

34. Divakar B, Mistry SD, Kantharia ND. The study of adverse drug reactions (ADRs) in HIV patients taking highly active antiretroviral therapy in art centre, $\mathrm{NCH}$, surat, India. IJMPS. 2012; 3(2): 09-18. 
35. Lazarou J, Pomeranz BH, Corey PN. Incidence of adverse drug reactions in hospitalized patients: a meta-analysis of prospective studies. JAMA. 1998; 279(15): 1200-5.

36. Chelkeba L, Abdissa G. Assessment of ART adverse reactions and determinants at primary hospital in Ethiopia. Int J Basic Clin Pharmacol. 2013; 2(2): 208-15.

37. Mengesha A. Assessment of adherence to antiretroviral therapy among 422 patients on ART at the ministry of national defense force hospitals [dissertation]. Ethiopia: Addis Ababa Univ; 2005; 18-22.

38. Kumarasamy N, Vallabhaneni S, Cecelia AJ, Yepthomi T, Balakrishnan $\mathrm{P}$, Saghayam $\mathrm{S}$, et al. Reasons for modification of generic highly active antiretroviral therapeutic regimens among patients in southern India. J Acquir Immune Defic Syndr. 2006; 41(1): 53-8.

39. Bhuvana KB, Hema NG, Sangeetha. A prospective observational study of adverse drug reactions to antiretroviral therapy: type and risk factors in a tertiary care teaching hospital. Int J Basic Clin Pharmacol. 2014; 3(2): 380-4.

40. Agu KA, Oparah AC, Ochei UM. Improving Monitoring and Reporting of Adverse Drug Reactions (ADRs) in HIV positive patients on Antiretroviral Therapy (ART) in Nigeria. J Basic Clin Pharm. March 2012-May 2012; 3(2): 299-313.

41. UN AIDS, JUN PoHA. Global report: UNAIDS report on the global AIDS epidemic 2010.UNAIDS Geneva; 2010
42. Reisler RB, Han C, Burman WJ, Tedaldi EM, Neaton JD. Grade 4 events are as important as AIDS events in the era of HEART. J Acquir Immune Defic Syndr. 2003; 34(4): 379-86

43. Munir P, Kevin PB. HIV and drug allergy. Current Opinion in Allergy \& Clinical Immunology 2001; 1(4): 311-6.

44. d'ArminioMonforte A, Lepri AC, Rezza G, Pezzotti P, Antinori A, Phillips AN, et al. Insights into the reasons for discontinuation of the first highly active antiretroviral therapy (HAART) regimen in a cohort of antiretroviral naïve patients. I.CO.N.A. Study Group. Italian Cohort of Antiretroviral-Naïve Patients. AIDS. 2000; 14(5): 499-507.

45. Eron JJ, Yetzer ES, Ruane PJ, Becker S, Sawyer GA, Fisher RL, et al. Efficacy, safety, and adherence with a twice-daily combination lamivudine/zidovudine tablet formulation, plus a protease inhibitor, in HIV infection. AIDS. 2000; 14(6): 671-81.

46. WHO. HIVIAIDS Programme: Strengthening health services to fight. HIV/ AIDS Antiretroviral therapy for hiv infection in adults and adolescents: Recommendations for a public health approach. Revision; 2006.

47. Hoffmann B. Management of Side Effects of ART. HIV Medicine Journal. 2005; 6(4): 263-82 